\title{
DERIVING FUNCTION-FAILURE SIMILARITY INFORMATION FOR FAILURE-FREE ROTORCRAFT COMPONENT DESIGN
}

\author{
Rory A. Roberts \\ Graduate Research Assistant \\ Department of Mechanical Engineering \\ University of Missouri-Rolla \\ Rolla, MO 65409 \\ rroberts@umr.edu
}

\author{
Robert B. Stone, Ph.D. ${ }^{\dagger}$ \\ Assistant Professor \\ Department of Basic Engineering \\ University of Missouri-Rolla \\ Rolla, MO 65409 \\ rstone@umr.edu \\ 573-341-4086
}

\author{
Irem Y. Tumer, Ph.D. \\ Research Scientist \\ Computational Sciences Division \\ NASA Ames Research Center \\ itumer@mail.arc.nasa.gov \\ Moffett Field, CA 94035 \\ 650-604-2976
}

\begin{abstract}
Performance and safety are the top concerns of high-risk aerospace applications at NASA. Eliminating or reducing performance and safety problems can be achieved with a thorough understanding of potential failure modes in the design that lead to these problems. The majority of techniques use prior knowledge and experience as well as Failure Modes and Effects as methods to determine potential failure modes of aircraft. The aircraft design needs to be passed through a general technique to ensure that every potential failure mode is considered, while avoiding spending time on improbable failure modes. In this work, this is accomplished by mapping failure modes to certain components, which are described by their functionality. In turn, the failure modes are then linked to the basic functions that are carried within the components of the aircraft. Using the technique proposed in this paper, designers can examine the basic functions, and select appropriate analyses to eliminate or design out the potential failure modes. This method was previously applied to a simple rotating machine test rig with basic functions that are common to a rotorcraft. In this paper, this technique is applied to the engine and power train of a rotorcraft, using failures and functions obtained from accident reports and engineering drawings.
\end{abstract}

\section{KEYWORDS}

Failure analysis; Functional modeling; Function-failure commonality; Functional decomposition for product design; Failurefree component design.

\section{INTRODUCTION}

Failures in aircraft components in high-risk applications are unacceptable in terms of safety and performance. In this work, methods of recording, understanding, and predicting failure modes are regarded to be essential to advance the field of fault monitoring and failure prevention [1-4]. In designing a new product or redesigning an existing product, designers often draw similarities between the new product and other related products [5]. This provides the designer with possible failure modes that may occur in the parts of the new design through experience with the similar designs. Unfortunately this does not supply all possible failure modes. It is generally not possible to analyze all possible failure modes that could occur in the new design only through comparisons with similar products. Designers need a fundamental way to capture and interpret past failures and utilize that information in the new design.

To help with this goal, the fundamentals of a design-aid tool was presented by Tumer and Stone in [6] to explore the connection between failure modes and the functionality of components and form a tool that designers may use to understand and prevent failures during conceptual and embodiment design. If this correlation between failure modes and functionality of the components can be established, then component solutions for each function can potentially be designed to eliminate or significantly reduce a given failure mode [6].

The focus of this paper is to decompose realistic products, in this case a rotorcraft, into their basic components and then decompose the components into their functionality. We hold that components have a "commonality" at some basic level in terms of their functionality and failure modes. The common modes of failure can be determined once the functionality of the component or product is established. Once these failure modes are paired to these basic functions, then a larger family of components and systems can be considered. Using this generalization, this work formalizes the process of feeding back failure mode and reliability information into design and manufacturing phases by transforming the information into a form that can be used effectively by engineers $[6-8]$. 
APPLICATION: ROTORCRAFT COMPONENT FAILURES

Helicopters have been a major safety concern to all types of agencies that use them for everyday operations. NASA has taken steps to help prevent failures and increase safety in their rotorcraft division. The probability of fatalities in rotorcraft accidents is higher than in other aircraft [9]. The preservation of human life is NASA's number one concern. To address this concern, it is necessary to expose potential failures modes that could occur during operation early in the design stages in order to reduce the chances of failure. In this paper, the engine and power train of a Bell 206 helicopter were studied for this purpose. Diagrams of the compressor, gas producer, and power turbine assemblies of the Allison 250 engine are presented for reference in Figure $1 \mathrm{a}, 1 \mathrm{~b}$, and $\mathrm{ic}$, respectively [10].

To examine and gather data from the research helicopters used in the rotorcraft division, NASA Ames Research Center was visited in July of 2001. The Bell OH-58A was one the helicopters that was examined, which is the sister military model of the Bell 206 civilian model. The OH-58A at NASA Ames was a test helicopter for failure analysis through monitoring vibration and noise signal behaviors [11]. Communication with Major David R. Arterburn provided information on the systems and maintenance of systems within the OH-58A helicopter [12]. Finally, accident reports published by the National Transportation Safety Board (NTSB) were studied thoroughly to extract common failure modes $[9,13]$.

There were 29 components and subsystems that were identified in the Bell 206 turbine engine and power train. In the NTSB reports, there were ten different types of failure modes recorded for these 29 components by the NTSB since 1983 [13]. The failure mode data gathered from the NTSB reports with respect to the components was formed into a matrix that is used in matrix manipulations to create design tools as described later in this paper [12]. In particular, there were 1000 reports that involved the Bell 206 . The reports were reviewed and all reports with component failures for the engine and power train were noted. There were 69 cases of component failures for the engine and power train recorded. The remaining reports mostly consisted of error in pilot judgment. Some examples are misjudgment in fuel reserves, forgetting to detach all tie downs, collisions into power lines, and fuel contamination. Most of the reports consisted of carelessness, which could be addressed by better training and procedures.

\section{FUNCTION-FAILURE METHOD: A DESIGN TOOL}

The function-failure method was first presented by Tumer and Stone [6]. The method was based on previous work presented by Stone et al. to derive the similarity between different designs based on functionality, used to provide a repository for designers $[8,14]$. In this work, the method was presented as a design-aid tool that extended the idea of similarities to failure detection $[6,11]$. In this paper, we apply the function-failure method for failure detection in rotorcraft component design, to capture failure-function similarity in failure-prone components [6]. Specifically, the method is applied to the engine and power train components in a Bell 206 helicopter to test and prove the concept, using failures reported by NTSB.

The function-failure method is provided primarily as a designaid tool. Once failure modes in high-risk aerospace applications have been linked to the functionality of components, the designer can draw conclusions on how to design or redesign the components. Early in the design stage the components can be altered to be less susceptible to the failure mode. If possible, the component can be replaced by another component that performs the similar functions, but is not affected by the failure mode at hand.

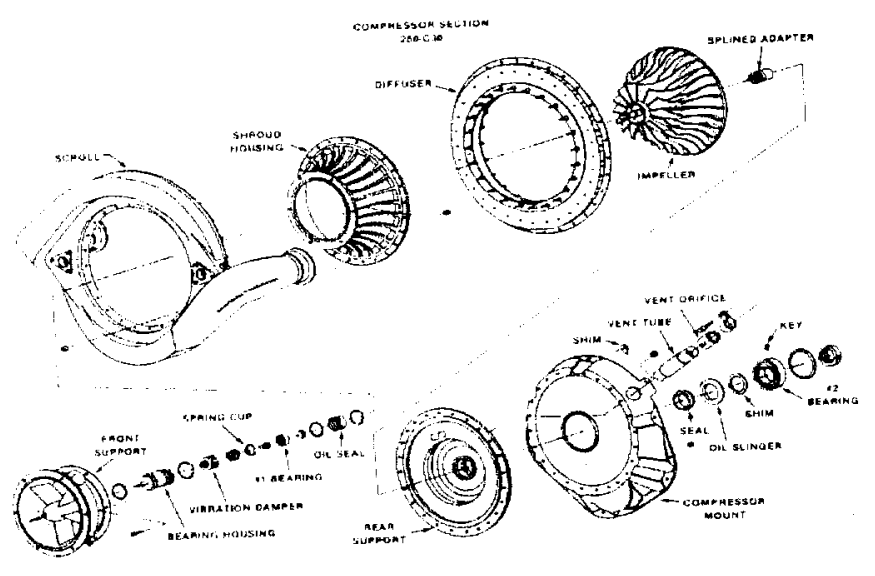

(a)

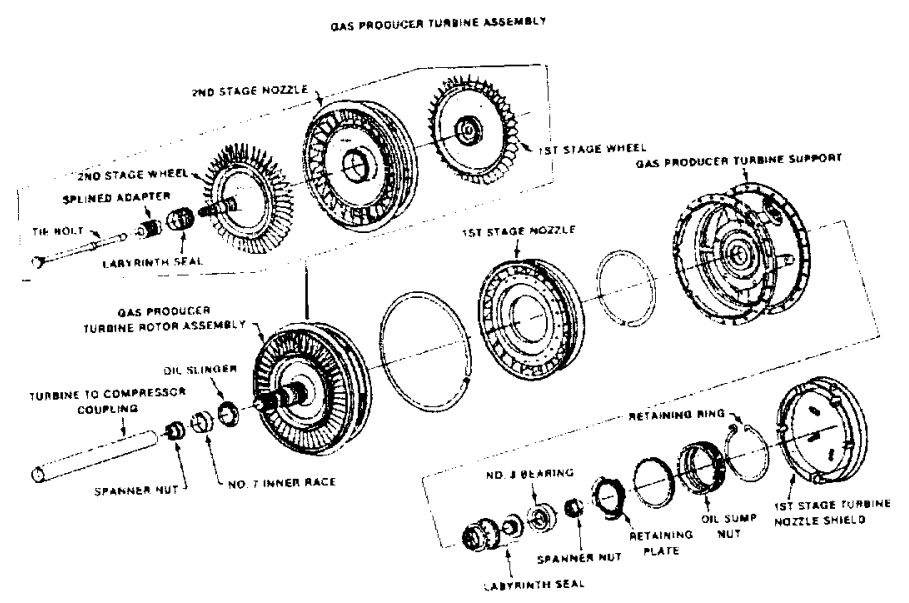

(b)

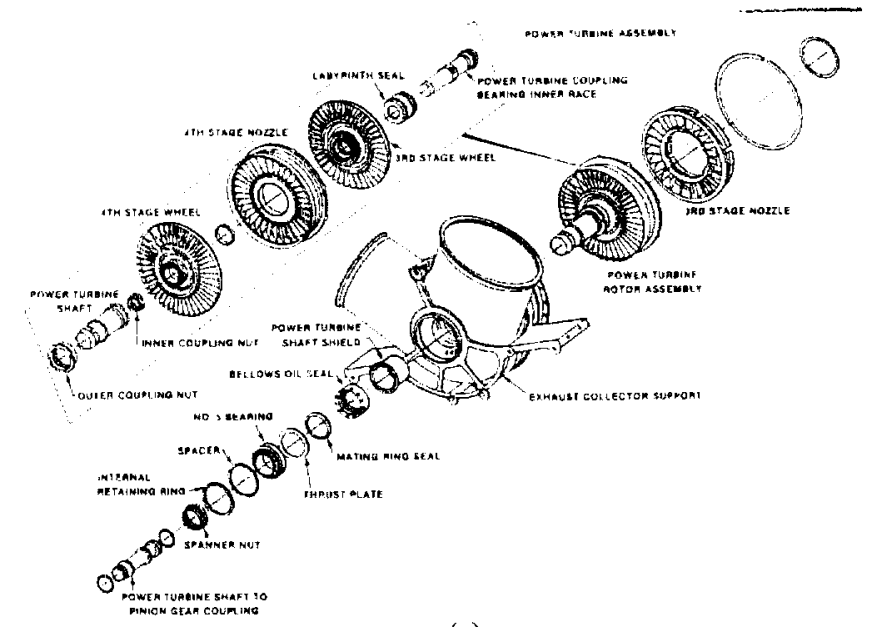

(c)

Figure 1. (a) compressor assembly, (b) gas producer assembly, and (c) power turbine assembly of the Allison 250 engine. 
Table 1. Failure vector.

\begin{tabular}{ll}
\hline & Failure \\
\hline \hline F1 & : bond failure \\
F2 & : corrosion \\
F3 & : fatigue \\
F4 & : fracture \\
F5 & : fretting \\
F6 & : galling and siezure \\
F7 & : human \\
F8 & : stress rupture \\
F9 & : thermal shock \\
F10 & : wear
\end{tabular}

\section{Preliminary Matrix Computations}

The engine and power train of the helicopter were broken down into components and subsystems. Let $\mathrm{C}$ be a $29 \times 1$ vector of the subsystems or components of the engine and power train. Let $\mathbf{F}$ be a 10 $x 1$ vector of the failures modes that were found in NTSB accident reports involving the Bell 206 helicopter that have occurred since 1983. Vectors $\mathbf{F}$ and $\mathbf{C}$ are found in Tables 1 and 2 respectively.

The failure information is represented by weaving the individual vectors (containing information on failure modes, functionality and components) into matrices of information useful for computation. The failure modes are recorded with respect to components and subsystems. In the component-failure matrix $\mathbf{C F}$, the rows represent the components and columns represent the failure modes. The matrix CF is found in Table 3 in binary form. A " 1 " is given if the failure mode occurred for the component and a " 0 " otherwise. Figure 2 provides a more visual representation of the component-failure mode data. The matrix from Table 3 was used to construct the chart.

Next, the functional model for the components of the engine and the power train are derived. Let $\mathbf{E}$ be a $24 \times 1$ vector containing the elemental functions and their flows describing the components of the engine and power train. Vector $\mathbf{E}$ is found in Table 4 . A matrix was constructed by weaving vector $\mathbf{E}$ with $\mathbf{C}$. The functions are represented in the rows and the components are represented in the columns. The function-component matrix $(\mathbf{E C})$ is in Table 5. For the rows of the matrix, the energy flows of the functions are mechanical energy $=$ me, thermal energy $=$ th, pneumatic energy $=$ pn. The elements in the matrix provide information for what function each component performs. The matrix is in binary form. A " 1 " is given if the component performs the function and a " 0 " otherwise. The $\mathbf{E C}$ is similar to the product-function matrix $\Phi$ found in previous work [8], except that $\mathbf{E C}$ gives information about the functionality of the components rather than the entire product. Once the componentfailure and the function-component matrix are constructed, the function-failure matrix, EF, can be computed as:

$$
\mathbf{E F}=\mathbf{E C} \times \mathbf{C F}
$$

Table 2. Component vector.

\begin{tabular}{|c|c|}
\hline & Component \\
\hline C1 & : air discharge tubes \\
\hline $\mathrm{C} 2$ & : bearing \\
\hline C3 & : bleed valve \\
\hline $\mathrm{C4}$ & : bolt \\
\hline $\mathrm{C5}$ & : compressor case \\
\hline C6 & : compressor mount \\
\hline $\mathrm{C7}$ & : compressor wheel \\
\hline $\mathrm{C8}$ & : coupling \\
\hline $\mathrm{Cg}$ & : diffuser scroll \\
\hline C10 & : exhaust collector \\
\hline C11 & : fire wall \\
\hline C12 & : front diffuser \\
\hline C13 & : front support \\
\hline C14 & : governor \\
\hline C15 & : housing \\
\hline C16 & : impeller \\
\hline C17 & : mount \\
\hline C18 & : nozzle \\
\hline C19 & : nozzle sheild \\
\hline $\mathrm{C2O}$ & : 'O' ring \\
\hline $\mathrm{C21}$ & : P3 line \\
\hline $\mathrm{C} 22$ & : plastic lining \\
\hline $\mathrm{C} 23$ & : pressure control line \\
\hline $\mathrm{C} 24$ & : pylon isolater mount \\
\hline C25 & : rear diffuser \\
\hline C26 & : rotor \\
\hline $\mathrm{C} 27$ & : shaft \\
\hline $\begin{array}{l}\mathrm{C} 28 \\
\mathrm{C}\end{array}$ & $\begin{array}{l}\text { spur adapter gearshaft } \\
\text { turbine wheel }\end{array}$ \\
\hline C29 & : turbine wheel \\
\hline
\end{tabular}

The function-failure matrix is in Table 6. Matlab was used to perform the computations to find the function-failure matrix. The elements in $\mathbf{E F}$ relate the failure modes to the elemental functions. Each element ef $_{i j}$ indicates how many components solving the function presented by the ith row experience the failure mode represented in the jth column.

When designing a new product or in this case a new design for an engine or power train of a rotorcraft, the designer constructs a function-component matrix for the design. The function-failure matrix EF is cross-multiplied by the transpose of the functioncomponent matrix EC to obtain a component-failure matrix, defined as:

$$
\mathbf{C F}=\mathbf{E} C^{\mathrm{T}} \times \mathbf{E F}
$$

This gives CF, the component-failure matrix, which provides the possible failures that a component may experience during operation. This allows the designer to design out the failure modes or change out components to eliminate or reduce the failure modes early in the design stages. 
Table 3. Component-failure mode matrix (CF).

\begin{tabular}{|c|c|c|c|c|c|c|c|c|c|c|}
\hline & $\bar{L}$ & $\underset{\sim}{\mathbb{N}}$ & $\dddot{m}$ & 妾 & $\stackrel{0}{\Perp}$ & 电 & E & $\underset{\mathbb{L}}{\infty}$ & 足 & 은 \\
\hline & $\begin{array}{l}\stackrel{0}{5} \\
\stackrel{\mathbb{N}}{0} \\
8 \\
\end{array}$ & $\begin{array}{l}5 \\
\frac{5}{5} \\
0 \\
0 \\
0\end{array}$ & 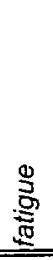 & 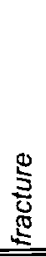 & $\stackrel{9}{\Xi}$ & 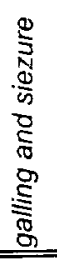 & $\stackrel{\varepsilon}{\xi}$ & 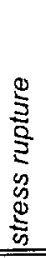 & 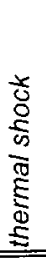 & 高 \\
\hline C1 : air discharge tubes & 0 & 0 & 0 & 0 & 0 & 0 & 0 & 0 & 0 & $\overline{0}$ \\
\hline C2 : bearing & 0 & 0 & 1 & 0 & 0 & 1 & 0 & 0 & 1 & 1 \\
\hline C3 : bleed valve & 0 & 0 & 0 & 0 & 0 & 0 & 0 & 0 & 0 & 0 \\
\hline C4 : bolt & 0 & 0 & 1 & 0 & 1 & 0 & 0 & 0 & 0 & 1 \\
\hline C5 : compressor case & 0 & 1 & 0 & 0 & 0 & 0 & 0 & 0 & 0 & 0 \\
\hline C6 : compressor mount & 0 & 0 & 1 & 0 & 0 & 0 & 0 & 0 & 0 & 0 \\
\hline C7 : compressor wheel & 0 & 0 & 1 & 0 & 0 & 0 & 0 & 1 & 1 & 0 \\
\hline C8: coupling & 0 & 0 & 1 & 0 & 0 & 0 & 0 & 0 & 0 & 1 \\
\hline $\begin{array}{l}\text { C9: diffuser scroll } \\
\text { C10: exhaust collector }\end{array}$ & $\begin{array}{l}0 \\
0\end{array}$ & $\begin{array}{l}0 \\
0\end{array}$ & $\begin{array}{l}0 \\
0\end{array}$ & $\begin{array}{l}0 \\
0\end{array}$ & $\begin{array}{l}0 \\
0\end{array}$ & $\begin{array}{l}0 \\
0\end{array}$ & $\begin{array}{l}0 \\
0\end{array}$ & $\begin{array}{l}0 \\
0\end{array}$ & $\begin{array}{l}0 \\
0\end{array}$ & $\begin{array}{l}0 \\
0\end{array}$ \\
\hline C11 : fire wall & 0 & 0 & 0 & 0 & 0 & 0 & 0 & 0 & 0 & 0 \\
\hline C12 : front diffuser & 0 & 0 & 0 & 0 & 0 & 0 & 0 & 0 & 0 & 0 \\
\hline C13 : front support & 0 & 0 & 0 & 0 & 0 & 0 & 0 & 0 & 0 & 0 \\
\hline C14: governor & 0 & 0 & 1 & 1 & 0 & 0 & 0 & 0 & 0 & 1 \\
\hline C15: housing & 0 & 0 & 0 & 0 & 0 & 0 & 0 & 0 & 1 & 1 \\
\hline C16: impeller & 0 & 0 & 0 & 0 & 0 & 0 & 0 & 0 & 0 & 0 \\
\hline C17 : mount & 0 & 0 & 1 & 0 & 0 & 0 & 0 & 0 & 0 & 0 \\
\hline C18: nozzle & 0 & 0 & 0 & 0 & 0 & 0 & 0 & 0 & 0 & 0 \\
\hline C19: nozzle sheild & 0 & 0 & 0 & 0 & 0 & 0 & 0 & 0 & 0 & 0 \\
\hline C20: 'O'ring & 0 & 0 & 0 & 0 & 0 & 0 & 1 & 0 & 0 & 1 \\
\hline C21:P3 line & 0 & 0 & 0 & 0 & 0 & 0 & 0 & 0 & 0 & 1 \\
\hline C22 : plastic lining & 0 & 0 & 0 & 0 & 0 & 0 & 0 & 0 & 0 & 0 \\
\hline C23: pressure control line & 0 & 0 & 1 & 0 & 1 & 0 & 0 & 0 & 0 & 0 \\
\hline C24 : pylon isolater mount & 0 & 0 & 0 & 0 & 0 & 0 & 0 & 0 & 0 & 1 \\
\hline C25 : rear diffuser & 0 & 0 & 0 & 0 & 0 & 0 & 0 & 0 & 0 & 0 \\
\hline C26: rotor & 0 & 1 & 0 & 0 & 0 & 0 & 0 & 0 & 0 & 0 \\
\hline C27 : shaft & 1 & 1 & 0 & 0 & 0 & 0 & 0 & 0 & 1 & 0 \\
\hline C28 : spur adapter gearshaft & 0 & 0 & 1 & 0 & 0 & 0 & 0 & 0 & 0 & 0 \\
\hline C29: turbine wheel & 0 & 0 & 1 & 0 & 0 & 0 & 0 & 1 & 1 & 0 \\
\hline
\end{tabular}

A more visual representation of $\mathbf{E F}$ can be seen in Figure 3. The chart gives a faster method of identifying the function to failure mode relationship. Note that the function 'secure solid' accounts for the most failures occurring in components.

\section{Capturing Similarity for Design and Redesign}

Other matrix manipulations of the data may be done to obtain additional design information. These manipulations result in similarity matrices, which provide designers with a tool to account for and design against potential failure modes. There are several different types of similarity matrices. The needs of the designer will determine which way is most useful. Each of the similarity matrices may be derived from the preceding component-function and component-failure matrices.

First, consider the component-function similarity matrix $\ddot{\Lambda}_{C E}$. Here we transpose the component-function matrix and post-multiply it by itself. This gives an $m \times m(m=29)$ symmetric matrix. Mathematically, the component-function similarity matrix is defined as,
Table 4. Functionality vector $\mathrm{E}$.

\begin{tabular}{|c|c|}
\hline & Functionality \\
\hline E1 & : change gas \\
\hline E2 & : change th \\
\hline E3 & : convert me to $p n$ \\
\hline E4 & : convert th to pn \\
\hline E5 & : couple me \\
\hline E6 & : couple solid \\
\hline E7 & : distribute gas \\
\hline E8 & : export gas \\
\hline E9 & : guide gas \\
\hline E10 & : import gas \\
\hline E11 & : regulate gas \\
\hline E12 & : regulate liquid \\
\hline E13 & : regulate me \\
\hline E14 & : secure solid \\
\hline E15 & : stop liquid \\
\hline E16 & : stop me \\
\hline E17 & : stop mixture \\
\hline E18 & : stop solid \\
\hline E19 & : stop th \\
\hline E20 & : store gas \\
\hline E21 & : store solid \\
\hline E22 & : transfer gas \\
\hline E23 & : transfer me \\
\hline E24 & : transfer pn \\
\hline
\end{tabular}

where $\overline{\mathbf{E C}}$ is the normalized matrix of the component-function matrix EC, with the columns normalized to unity. Each of the elements $\mathrm{ec}_{i j}$ represents the similarity between the components $i$ and $j$ based on the elementary functions. The diagonal $(i=j)$ is all ones because the component is completely similar with itself. Similarly, if the value is 1 elsewhere, then the two components are completely similar to each other, and if the value is 0 , then the two components have no similarity (they do not share common elemental functions).

Next, the component-failure similarity matrix $\Lambda_{C F}$ is computed from the component-failure matrix, $C F$ (non-normalized). The component-failure similarity matrix is defined as:

$$
\hat{\Lambda}_{C F}=\mathbf{C F} \times \mathbf{C F}^{\mathrm{T}}
$$

The elements indicate the count of common failure modes that components experience. The diagonal simply returns the count of potential failure modes that a component experiences. 


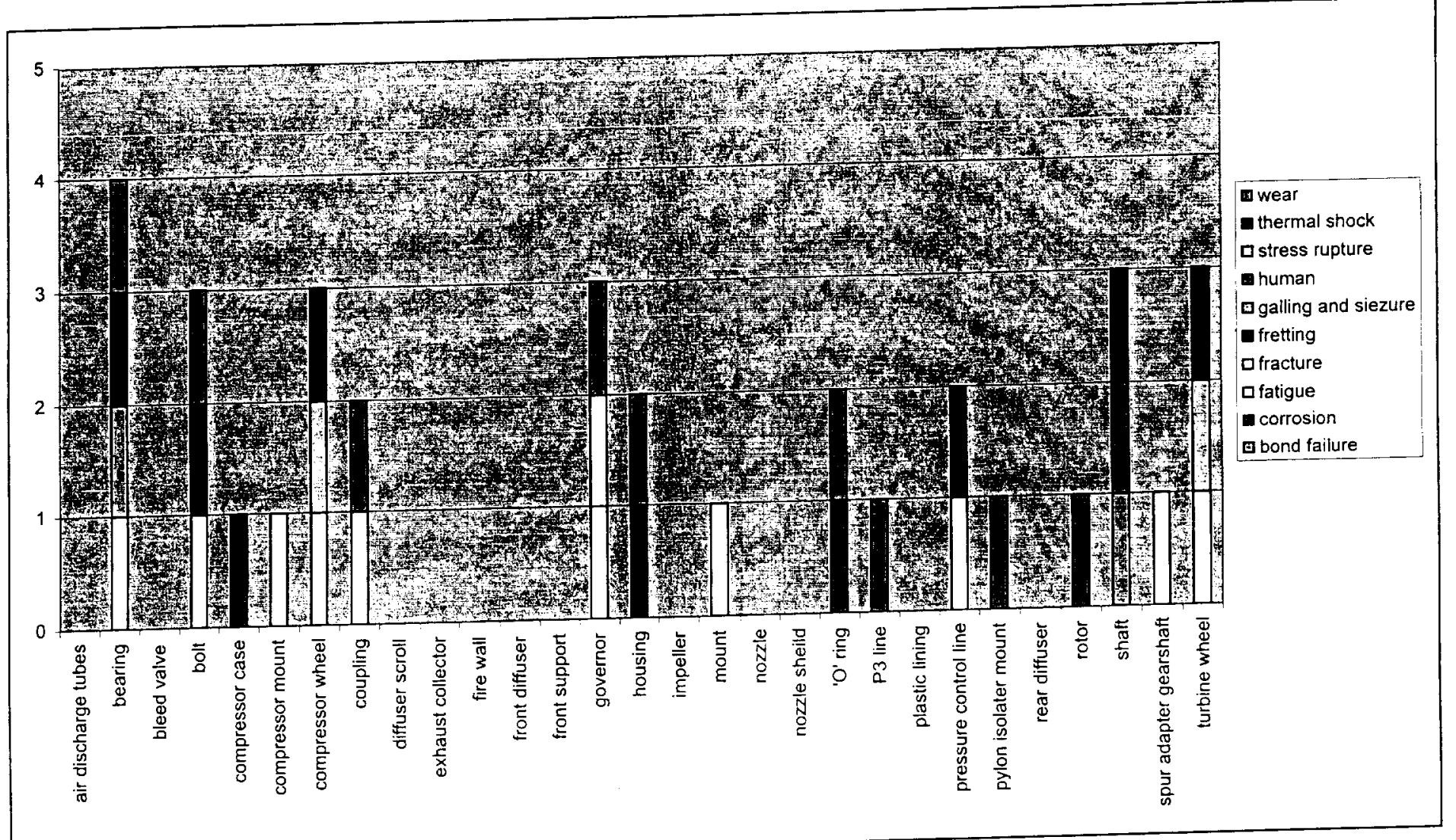

Figure 2. Bar chart of the Component-Failure matrix.

Finally, the similarity matrix for the failure-component matrix is calculated as:

$$
\hat{\Lambda}_{F C}=\mathbf{C F} \mathbf{F}^{\mathrm{T}} \times \mathbf{C F}
$$

The failure-component similarity matrix indicates the count of components that the failure modes have in common. The diagonal simply gives the count of how many components experience the failure mode represented by $i j$ (where $i=j$ ).

\section{Application to the Engine and Power Train of a Rotorcraft}

The similarity matrices are derived using the normalized $\overline{\mathbf{E C}}$ matrix and the non-normalized $\mathbf{C F}$ matrix in binary form from earlier. The normalized matrix $\overrightarrow{\mathbf{E C}}$ was computed and is presented in Table 7. The similarity matrix of the component-function matrix, $\ddot{\Lambda}_{C E}$, was also computed and is presented in Table 8 . The component-function similarity matrix, $\ddot{\Lambda}_{C E}$, communicates that components $C_{18}$ and $C_{7}$ (nozzle and compressor wheel) are similar in function and $C_{18}$ and $C_{16}$ (nozzle and impeller) are similar in function when one is projected onto the other. The following groups of components have complete similarity (indicated by 1.0 ) with respect to functionality: $C_{16}$ and $C_{7}$ (impeller and compressor wheel); $C_{23}$ and
$C_{1}$ (Pressure control line and air discharge tubes); $C_{23}$ and $C_{3}$ (plastic lining and bleed valve); $C_{17}, C_{5}, C_{6}$ and $C_{4}$ (mount, compressor case compressor mount, and bolt); $C_{28}$ and $C_{27}$ (spur adapter gearshaft and shaft); and $C_{9}$ and $C_{10}$ (diffuser scroll and exhaust collector). This indicates that some of these components can be replaced by other similar components or redesigned with influence from the design of the similar components in order to reduce or eliminate particular failure modes.

The components can be examined for common failure modes by examining the component-failure similarity matrix $\hat{\Lambda}_{C F}$, shown in

Table 9. Component $C_{2}$ (bearing) experiences the most failure modes, equal to four indicated in the diagonal. Components $C_{7}$ and $C_{29}$ (compressor wheel and turbine wheel) share three common failure modes (fatigue, stress rapture, and thermal shock), which is the total number of failure modes each component experiences. Several components share two common failure modes. For example, $C_{4}$ and $C_{8}$ (bolt and coupling) have two common failure modes (fatigue and wear). Some components do not experience any failure modes because the data collected for component failures of the engine and the power train of rotorcrafts did not include any failures for these components, but the function model included the components. The components were added to complete the systems of the rotorcraft.

The failure-component similarity matrix is shown in Table 10. $F_{3}$ and $F_{10}$ (fatigue and wear) have four common components. In the diagonal, $F_{3}$ (fatigue) has ten components that experience fatigue, 
Table 5. The function-component matrix, EC

\begin{tabular}{|c|c|c|c|c|c|c|c|c|c|c|c|c|c|c|c|c|c|c|c|c|c|c|c|c|c|c|c|c|c|c|}
\hline & & $\overline{0}$ & $\mathcal{J}$ & 8 & J & క & 8 & $\hat{U}$ & $\stackrel{\infty}{0}$ & $g$ & 웅 & $\bar{j}$ & $\frac{N}{0}$ & $\frac{m}{j}$ & $\frac{\pi}{0}$ & $\frac{10}{0}$ & $\frac{\omega}{\dot{U}}$ & $\bar{U}$ & $\stackrel{\infty}{0}$ & $\frac{\pi}{U}$ & 엉 & $\overline{\mathcal{J}}$ & $\mathcal{J}$ & $\tilde{\mathcal{U}}$ & $\stackrel{\mathbb{J}}{\mathcal{U}}$ & ปี & త్ర & $\hat{\mathcal{J}}$ & $\stackrel{\infty}{\mathcal{U}}$ & స్తి \\
\hline & & 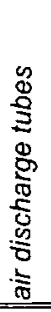 & 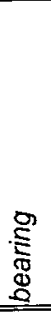 & 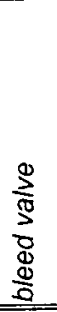 & \pm & 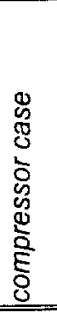 & 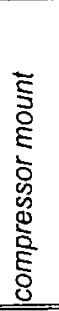 & 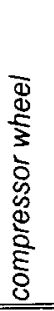 & $\begin{array}{r}9 \\
\text { 응 } \\
8 \\
\end{array}$ & 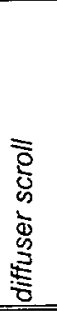 & 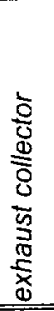 & 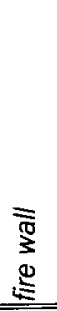 & 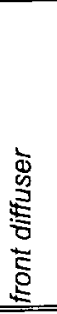 & $\begin{array}{l}5 \\
8 \\
\frac{5}{2} \\
5 \\
5 \\
\text { 잉 }\end{array}$ & $\begin{array}{l}\grave{g} \\
\stackrel{5}{0} \\
\text { o } \\
0\end{array}$ & $\begin{array}{l}\stackrel{Q}{5} \\
5 \\
\\
\end{array}$ & 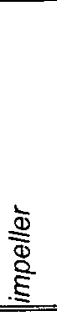 & $\begin{array}{l}\bar{S} \\
\stackrel{\Xi}{\Xi} \\
\end{array}$ & $\begin{array}{l}\frac{D}{N} \\
\text { N } \\
\end{array}$ & 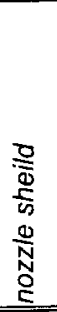 & $\begin{array}{l}\underline{g} \\
\stackrel{\Sigma}{5} \\
0 \\
\end{array}$ & 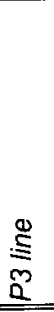 & 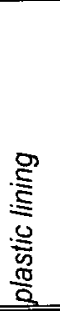 & 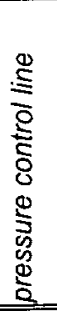 & 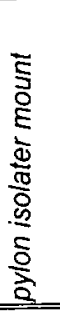 & 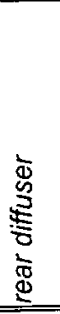 & ㅎํㄹ & $\begin{array}{l}\frac{W}{\infty} \\
\text { 齐 } \\
\end{array}$ & 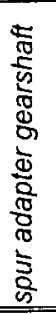 & 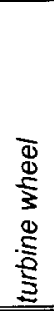 \\
\hline$\overline{\mathrm{E} 1}$ & change gas & 0 & 0 & 0 & 0 & 0 & 0 & 1 & 0 & 0 & 0 & 0 & 0 & 0 & 0 & 0 & 1 & 0 & 1 & 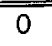 & 0 & 0 & 0 & 0 & 0 & 0 & 1 & 0 & 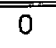 & 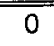 \\
\hline E2 & change th & 0 & 1 & 0 & 0 & 0 & 0 & 0 & 0 & 0 & 0 & 0 & 0 & 0 & 0 & 0 & 0 & 0 & 0 & 0 & 0 & 0 & 0 & 0 & 0 & 0 & 0 & 0 & 0 & 0 \\
\hline E3 & convert me to pn & 0 & 0 & 0 & 0 & 0 & 0 & 1 & 0 & 0 & 0 & 0 & 0 & 0 & 0 & 0 & 1 & 0 & 0 & 0 & 0 & 0 & 0 & 0 & 0 & 0 & 0 & 0 & 0 & 0 \\
\hline E4 & convert on to me & 0 & 0 & 0 & 0 & 0 & 0 & 0 & 0 & 0 & 0 & 0 & 0 & 0 & 0 & 0 & 0 & 0 & 0 & 0 & 0 & 0 & 0 & 0 & 0 & 0 & 0 & 0 & 0 & 1 \\
\hline E5 & couple me & 0 & 0 & 0 & 0 & 0 & 0 & 0 & 1 & 0 & 0 & 0 & 0 & 0 & 0 & 0 & 0 & 0 & 0 & 0 & 0 & 0 & 0 & 0 & 0 & 0 & 0 & 0 & 0 & 0 \\
\hline E6 & couple solid & 0 & 0 & 0 & 0 & 0 & 0 & 0 & 1 & 0 & 0 & 0 & 0 & 0 & 0 & 0 & 0 & 0 & 0 & 0 & 0 & 0 & 0 & 0 & 0 & 0 & 0 & 0 & 0 & 0 \\
\hline E7 & distribute gas & 0 & 0 & 0 & 0 & 0 & 0 & 0 & 0 & 1 & 1 & 0 & 0 & 0 & 0 & 0 & 0 & 0 & 0 & 0 & 0 & 0 & 0 & 0 & 0 & 0 & 0 & 0 & 0 & 0 \\
\hline E8 & export gas & 0 & 0 & 0 & 0 & 0 & 0 & 0 & 0 & 1 & 1 & 0 & 0 & 0 & 0 & 0 & 0 & 0 & 0 & 0 & 0 & 0 & 0 & 0 & 0 & 0 & 0 & 0 & 0 & 0 \\
\hline E9 & guide gas & 0 & 0 & 0 & 0 & 0 & 0 & 1 & 0 & 0 & 0 & 0 & 0 & 1 & 0 & 0 & 1 & 0 & 1 & 0 & 0 & 0 & 0 & 0 & 0 & 0 & 0 & 0 & 0 & 0 \\
\hline E10 & import gas & 0 & 0 & 0 & 0 & 0 & 0 & 0 & 0 & 0 & 0 & 0 & 0 & 1 & 0 & 0 & 0 & 0 & 0 & 0 & 0 & 0 & 0 & 0 & 0 & 0 & 0 & 0 & 0 & 0 \\
\hline E11 & regulate gas & 0 & 0 & 1 & 0 & 0 & 0 & 0 & 0 & 0 & 0 & 0 & 0 & 0 & 0 & 0 & 0 & 0 & 0 & 0 & 0 & 0 & 1 & 0 & 0 & 0 & 0 & 0 & 0 & 0 \\
\hline E12 & regulate liquid & 0 & 0 & 0 & 0 & 0 & 0 & 0 & 0 & 0 & 0 & 0 & 0 & 0 & 1 & 0 & 0 & 0 & 0 & 0 & 0 & 0 & 0 & 0 & 0 & 0 & 0 & 0 & 0 & 0 \\
\hline E13 & regulate me & 0 & 0 & 0 & 0 & 0 & 0 & 0 & 0 & 0 & 0 & 0 & 0 & 0 & 0 & 0 & 0 & 0 & 0 & 0 & 0 & 0 & 0 & 0 & 1 & 0 & 0 & 0 & 0 & 0 \\
\hline E14 & secure solid & 0 & 1 & 0 & 1 & 1 & 1 & 0 & 0 & 0 & 0 & 0 & 0 & 1 & 0 & 1 & 0 & 1 & 0 & 0 & 0 & 0 & 0 & 0 & 1 & 1 & 0 & 0 & 0 & 0 \\
\hline E15 & stop liquid & 0 & 0 & 0 & 0 & 0 & 0 & 0 & 0 & 0 & 0 & 0 & 0 & 0 & 0 & 0 & 0 & 0 & 0 & 0 & 1 & 0 & 0 & 0 & 0 & 0 & 0 & 0 & 0 & 0 \\
\hline E16 & stop me & 0 & 0 & 0 & 0 & 0 & 0 & 0 & 0 & 0 & 0 & 0 & 0 & 0 & 0 & 0 & 0 & 0 & 0 & 1 & 0 & 0 & 0 & 0 & 0 & 0 & 0 & 0 & 0 & 0 \\
\hline E17 & stop mixture & 0 & 0 & 0 & 0 & 0 & 0 & 0 & 0 & 0 & 0 & 0 & 0 & 0 & 0 & 1 & 0 & 0 & 0 & 0 & 0 & 0 & 0 & 0 & 0 & 0 & 0 & 0 & 0 & 0 \\
\hline E18 & stop solid & 0 & 0 & 0 & 0 & 0 & 0 & 0 & 0 & 0 & 0 & 0 & 0 & 1 & 0 & 0 & 0 & 0 & 0 & 0 & 0 & 0 & 0 & 0 & 0 & 0 & 0 & 0 & 0 & 0 \\
\hline E19 & stop th & 0 & 1 & 0 & 0 & 0 & 0 & 0 & 0 & 0 & 0 & 1 & 0 & 0 & 0 & 0 & 0 & 0 & 0 & 0 & 0 & 0 & 0 & 0 & 0 & 0 & 0 & 0 & 0 & 0 \\
\hline E20 & store gas & 0 & 0 & 0 & 0 & 0 & 0 & 0 & 0 & 1 & 1 & 0 & 1 & 0 & 0 & 0 & 0 & 0 & 0 & 0 & 0 & 0 & 0 & 0 & 0 & 1 & 0 & 0 & 0 & 0 \\
\hline E21 & store solid & 0 & 0 & 0 & 0 & 0 & 0 & 0 & 0 & 0 & 0 & 0 & 0 & 0 & 0 & 1 & 0 & 0 & 0 & 0 & 0 & 0 & 0 & 0 & 0 & 0 & 0 & 0 & 0 & 0 \\
\hline E22 & transfer gas & 1 & 0 & 0 & 0 & 0 & 0 & 0 & 0 & 0 & 0 & 0 & 0 & 0 & 0 & 0 & 0 & 0 & 0 & 0 & 0 & 0 & 0 & 1 & 0 & 0 & 0 & 0 & 0 & 0 \\
\hline E23 & transfer me & 0 & 0 & 0 & 0 & 0 & 0 & 0 & 1 & 0 & 0 & 0 & 0 & 0 & 0 & 0 & 0 & 0 & 0 & 0 & 0 & 0 & 0 & 0 & 0 & 0 & 1 & 1 & 1 & 0 \\
\hline E24 & transfer pn & 0 & 0 & 0 & 0 & 0 & 0 & 0 & 0 & 0 & 0 & 0 & 0 & 0 & 0 & 0 & 0 & 0 & 0 & 0 & 0 & 1 & 0 & 0 & 0 & 0 & 0 & 0 & 0 & 0 \\
\hline
\end{tabular}

which is the most common failure mode through out the engine and power train of the rotorcraft. The failure modes $F_{3}$ and $F_{9}$ (fatigue and thermal shock) share three common components. There are many combinations of failure modes that do not occur together, which are indicated by a " 0 ".

\section{Use as a Potential Design-Aid Tool}

The similarity matrices provide information for possible replacements or redesign of certain characteristics for components. It also provides a way to search and rank component solutions that are similar in function and use design by analogy techniques to embody a design. The component-function similarity and component-failure similarity matrices identify possible component solutions that prevent potential failure modes. If, between functionally-similar components $\mathrm{A}$ and $\mathrm{B}$ (as determined by $\hat{\Lambda}_{C E}$ ), component $\mathrm{B}$ does not experience all of the same failure modes as component $A$ (as determined by $\hat{\Lambda}_{C F}$ ), then there is some characteristic of component B that could be incorporated into $A$ to improve its performance.

Consider the components $C_{16}$ and $C_{7}$ (impeller and compressor wheel), which have complete similarity in functionality and do not share any common failure modes as seen from? The two components could be used to redesign the other component by acknowledging what characteristics in each component reduces or eliminates the failures modes experienced by the other component and incorporating this information into the new design. Also, for the components that share common failure modes and functionality, the solution for reducing or eliminating a failure mode for one component could most likely be applied to the other component. This could be the case for $C_{17}$ and $C_{4}$ (mount and bolt), which have complete similarity and have the failure mode $F_{4}$ (fatigue) in common.

At last, the failure-component similarity matrix $\left(\Lambda_{F C}\right)$ gives a

mathematical picture of possible interactions between two or more failure modes. The elements indicate failure mode combinations that occur between components. These interactions can be used to direct component remedies that will possibly eliminate more than one failure mode. For the current FMEA and FTA techniques, this knowledge of failure modes occurring interactively would give designers a more complete list of the possible product failures to be investigated. 


\section{CONCLUSIONS AND FUTURE WORK}

In this paper, the function-failure method was applied to the engine and power train systems of rotorcraft to provide proof of the links between the functionality of a component to the potential failures of that component. The foundation of this paper lies on the fact that this link exists between the functionality of a component and its potential failure modes. This method provides rotorcraft designers an analytical means to capture systematic tradeoffs and design or redesign decisions based on similarities, to prevent potential failure modes. This method was applied earlier to a simple example using a rotating machinery test rig, to illustrate the potential of this method [6]. The purpose of the function-failure method is to aid NASA in the design of their high-risk aerospace endeavors, where safety is high priority when failures can lead to fatal accidents. In the application of the method in this paper, actual failure data was gathered from NTSB (national transportation safety board) reports and incorporated into the component-failure matrix, $\mathbf{C F}$,

For future work, other areas of collecting failure data could give a more complete CF matrix. Possible places to acquire failure data would be from the records of failures from manufacturers of these aircraft and the records of failures logged by the military applications of these aircrafts. Furthermore, a method of consistent component naming will be introduced. This will provide a common generic way of classifying and representing the components in the mapping failure-function method proposed in this paper. This mapping of the failure-function method is currently being applied to a wide range of products [15]. The goal is to provide all this information stored in a repository that can be used by designers, and to expand this to as many products as possible.

The repetition of occurrence of failure modes for components over the time period for which the data was gathered was not used in this paper. In the future, the frequency of occurrence of a particular failure mode for a component will be incorporated to give more insight of the more probable potential failure modes.
Table 6. Function-failure matrix (EF).

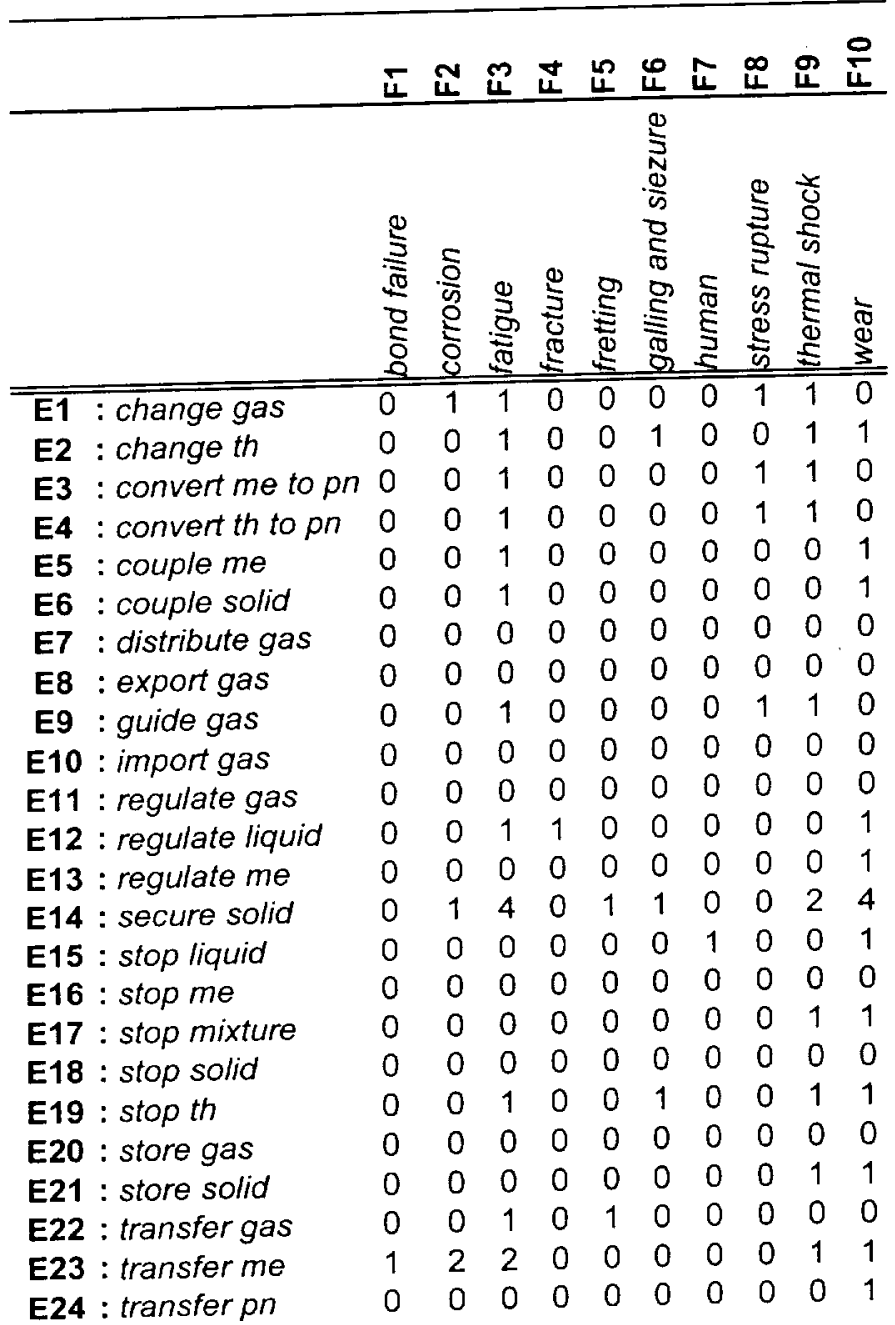




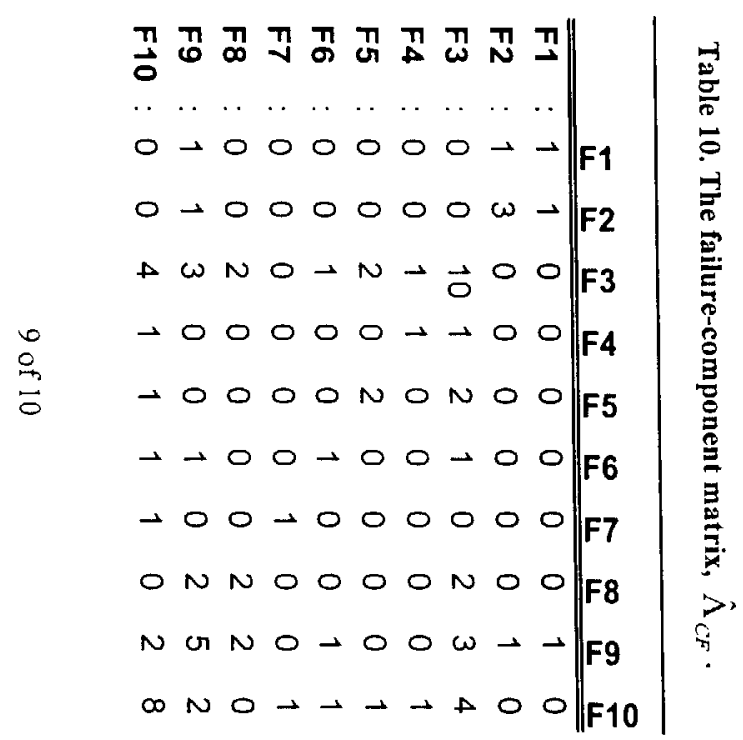

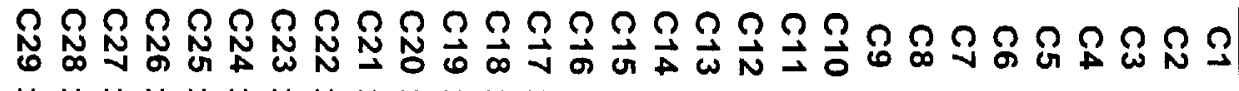

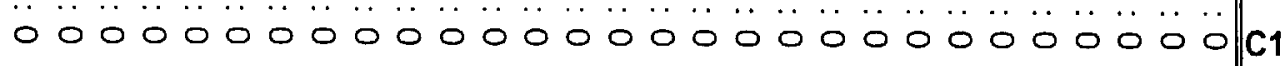
$N \rightarrow \rightarrow 0 O \rightarrow \rightarrow 0 \rightarrow-0 O \rightarrow O N N O O O O O N N \rightarrow O N O A O$ C2 00000000000000000000000000000 C3 $\rightarrow-O O O \rightarrow N O \rightarrow-O O \rightarrow O \rightarrow N O O O O O N \rightarrow \rightarrow 0 \omega O N O \mid C 4$ $00 \rightarrow-00000000000000000000-0000 \mid C 5$ $\rightarrow-0000 \rightarrow 00000 \rightarrow 00 \rightarrow 00000 \rightarrow-\rightarrow 0 \rightarrow 0 \rightarrow 0$ C6 $\omega \rightarrow+000 \rightarrow 00000 \rightarrow 0 \rightarrow-00000 \rightarrow \omega \rightarrow 0 \rightarrow 0 N 0 \mid C 7$

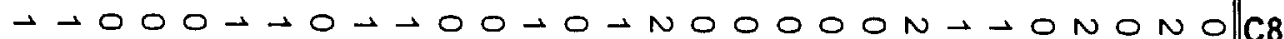
$00000000000000000000000000000 \mid C 9$ $00000000000000000000000000000 \mid c_{10}$ $00000000000000000000000000000 \mid c 11$ $00000000000000000000000000000 \mid C_{12}$ 00000000000000000000000000000 C13 $\rightarrow-000 \rightarrow-0 \rightarrow-00 \rightarrow 0 \rightarrow \omega 00000 N \rightarrow \rightarrow 0 N O N O C 14$ $-0 \rightarrow 00 \rightarrow 00 \rightarrow-0000 N \rightarrow 00000 \rightarrow-00 \rightarrow 0 N 0 \mid C 15$ 00000000000000000000000000000 C16 $\rightarrow \rightarrow 0000 \rightarrow 00000 \rightarrow 00 \rightarrow 00000 \rightarrow-\rightarrow 0 \rightarrow 0 \rightarrow 0$ C17 $00000000000000000000000000000 \mid 118$ $00000000000000000000000000000 \mid 119$ $00000 \rightarrow 00 \rightarrow N 0000 \rightarrow-00000 \rightarrow 000 \rightarrow 0 \rightarrow 0 l$ C20 $00000 \rightarrow 00 \rightarrow-0000 \rightarrow-00000 \rightarrow 000 \rightarrow 0 \rightarrow 0$ l 121 $00000000000000000000000000000 \mid C_{22}$ $\rightarrow-0000 n 00000 \rightarrow 00 \rightarrow 00000 \rightarrow \rightarrow-0 N 0 \rightarrow 0$ C $00000 \rightarrow 00 \rightarrow-0000 \rightarrow-00000+000 \rightarrow 0-0$ C24 $00000000000000000000000000000 \mid C 25$ $00 \rightarrow-00000000000000000000 \rightarrow 0000 \mid$ C26 $\rightarrow 0 w \rightarrow 0000000000 \rightarrow 0000000 \rightarrow 0 \rightarrow 00-0 \mid C 27$ $\rightarrow \rightarrow 0000 \rightarrow 00000 \rightarrow 00-00000 \rightarrow-\rightarrow 0-0-0$ - 128 $\omega \rightarrow \rightarrow 000 \rightarrow 00000 \rightarrow 0 \rightarrow-00000-\omega \rightarrow 0-0 N 0|| C 29$ 


\section{REFERENCES}

1. Collins, J.A., B.T. Hagan, and H.M. Bratt, The failureexperience matrix: A useful design tool. Journal of Engineering for Industry, 1976. August: p. 1074-1079.

2. Mitchell, J.S., Introduction to machinery analysis and monitoring. 2nd ed. 1993: PennWell Books.

3. Carter, A.D.S., Mechanical Réliability and Design. 1997: John Wiley \& Sons.

4. Smith, J.D., Gear Noise and Vibration. 1999: Marcel Dekker.

5. McAdams, D. and K.L. Wood. Quantitative measures for design by analogy. in Proceedings of the Design Engineering Technical Conferences. 2000. Baltimore, MD: ASME.

6. Tumer, I.Y. and R.B. Stone. Analytical method for mapping function to fallure during high-risk component development. in Proceedings of the Design Engineering Technical Conferences. 2001. Pittsburgh, PA: ASME.

7. Stone, R.B., K.L. Wood, and R.H. Crawford. Product architecture development with quantitative functional models. in Proceedings of the Design Engineering Technical Conferences. 1999. Las Vegas, NV: ASME.

8. Stone, R.B., K.L. Wood, and R.H. Crawford, Using quantitative functional models to develop product architectures. Design Studies, 2000. 21(3): p. 239-260.

9. Harris, F.D., E.F. Kasper, and L.E. Iseler, U.S. Civil Rotorcraft Accidents, 1963 through 1997. 2000.

10. Shafer, J., Fundamentals of Helicopter Maintenance. 1980 , Basin, WY: Aviation Maintenance Publishers, Inc.

11. Huff, E.M., I.Y. Tumer, and M. Mosher. An experimental comparison of transmission vibration responses from OH58C and AHI helicopters. in American Helicopter Society's 57th Annual Forum. 2001. Washington, D.C.

12. Arterburn, D.R., Personal Communications. 2001: NASA Ames Research Center.

13. NTSB, National Transportation Safety Board, http://www.ntsb.gov. 2001

14. Stone, R.B. and K.L. Wood, Development of a Functional Basis for Design. Journal of Mechanical Design, 2000. 122(December): p. 359-370.

15. Arunajadai, S.G., R.B. Stone, and I.Y. Tumer. A framework for creating a function-based design tool for failure mode identification. in Proceedings of the Design Engineering Technical Conferences (submitted for review). 2002. 